\title{
Estimation of leaf area in coffee leaves (Coffea arabica L.) of the Castillo ${ }^{\circledR}$ variety
}

\author{
Carlos Andrés Unigarro-Muñoz ('); Juan David Hernández-Arredondo ('); \\ Esther Cecilia Montoya-Restrepo ( $\left.{ }^{1}\right)$; Ruben Darío Medina-Rivera ( $\left.{ }^{2}\right)$; \\ Lizardo Norbey Ibarra-Ruales ( $\left.{ }^{2}\right)$; Claudia Yoana Carmona-González (²); \\ Claudia Patricia Flórez-Ramos $\left({ }^{1 *}\right)$
}

(') Centro Nacional de Investigaciones de Café (CENICAFÉ), Plant Physiology, Sede Planalto, km. 4 vía Chinchiná-Manizales, Manizales, Caldas, Colombia.

(2) Centro Nacional de Investigaciones de Café (CENICAFÉ), Biometric, Manizales, Caldas, Colombia.

$\left(^{*}\right)$ Corresponding author: claudia.florez@cafedecolombia.com

Received: Jan. 21, 2015; Accepted: May 25, 2015

\begin{abstract}
Allometric models based on measurements of single leaf dimensions or a combination there are useful tools for determining individual leaf area (LA) because they are non-destructive, precise, simple and economical methods. The present study was carried out at the Central Station Naranjal of Cenicafé, located in the Department of Caldas (Colombia), four models were defined using the variables length $(\mathrm{L})$ and/or width $(\mathrm{W})$ to estimate LA in coffee leaves of the Castillo ${ }^{\circledR}$ variety (Coffea arabica L.). Estimation of regression coefficients was performed using information recorded from 6,441 leaves (group 1), and their validation was performed using records from another 992 leaves (group 2). Leaves were collected from all strata of the canopy and ranged from 0.76 to $140 \mathrm{~cm}^{2}$ in LA. In addition to exhibiting coefficients of variation differing from zero based on t-tests at $1 \%$, the evaluated models possess coefficients of determination between 0.93 and 0.99 . Four expressions have developed and adjusted to estimate leaf area in individual leaves, based on the measurement of simple variables and non-destructive.
\end{abstract}

Key words: modeling, length, width.

\section{INTRODUCTION}

Coffee is cultivated in 56 countries located in tropical and subtropical regions of the world (ICO, 2013). Coffee agro-ecosystems support millions of farmers through the income they generate and the environmental services they offer (Castro-Tanzi et al., 2014). Coffee is one of the main crops grown in countries such as Brazil, Mexico, Colombia, Ethiopia and Kenya (Hein \& Gatzweiler, 2006). In Colombia, the area dedicated to coffee farms was approximately 949,000 hectares in 2014 , with coffee rust-resistant varieties being grown on $64 \%$ of the land (FNC, 2014). Among such varieties, the Castillo ${ }^{\circledR}$ variety is noteworthy, as are its regional components developed by the Colombian National Coffee Research Center (CENICAFÉ, based on its initials in Spanish) (Alvarado et al., 2005, 2009; Cortina et al., 2012).

Several studies have shown that leaf area (LA) plays a determinant role in light interception and, as a consequence, in processes such as vegetative growth, development rates, photosynthetic efficiency, evapotranspiration, the use of nutrients and water, and even the response to fertilizers (Blanco \& Folegatti, 2005; Goudriaan \& Van
Laar, 1994; Herbert, 2004; Williams \& Martinson, 2003). The productivity potential of the plant is determined by the leaf area available for carbon assimilation during its life cycle (Arcila \& Chaves, 1995). For this reason, quantifying LA is fundamental to assessing plant primary productivity (Pandey \& Singh, 2011) and as a functional component of crop modeling (Lizaso et al., 2003). In this context, the simple, economical and precise estimation of LA has been a subject that is widely discussed by scientists (Pandey \& Singh, 2011).

Methodologies aimed at quantifying LA may or may not be destructive (Ilkaee et al., 2011). In the first case, cutting the leaf is necessary, and measuring is performed using traditional methods such as copying on graph paper, photographing, or using a planimeter (Fallovo et al., 2008). However, the greatest limitation of such methodology is the impossibility of taking successive measurements through time on the same leaf. Additionally, the resulting defoliation may alter other experimental measurements (Fallovo et al., 2008). In certain cases, when the number of leaves to be assessed is high, quantification of LA is costly 
in time and resources (Antunes et al., 2008). Non-destructive methods, such as the use of a portable scanning planimeter, can be fast and precise (Daughtry, 1990) but are only feasible on small plants with few leaves (Nyakwende et al., 1997). Alternatively, analysis of images using software is also fast and precise (Bignami \& Rossini, 1996) but may be limited by not being user-friendly.

In this context, estimation of LA based on one or more leaf dimensions (length and width) is an economical, quick, reliable, non-destructive method that can be applied in situ (Beerling \& Fry, 1990; Fallovo et al., 2008; Lu et al., 2004; Serdar \& Demirsoy, 2006; Sousa et al., 2005; Williams \& Martinson, 2003) and is presently applicable (Galindo \& Clavijo, 2007). However, the precision of LA estimation does not take into account external factors such as leaf morphology (length/width ratio), which can vary among genotypes (Stoppani et al., 2003). Nevertheless, Antunes et al. (2008) did not find significant differences in leaf shape when evaluating eight coffee genotypes. Other factors, such as violating the assumptions of statistical models, require modification of such conclusions (Chatterjee \& Hadi, 2006). Several allometric models have been proposed to estimate LA in coffee (Antunes et al., 2008; Awantramani \& Gopalakrishna, 1965; Barros et al., 1973; Rey \& Alvarez, 1991; Valencia, 1973). In 1973, Valencia established an algorithm based on measuring the length of the midrib for the Caturra variety.

Taking into account the above discussion and considering the new coffee varieties produced at Cenicafé, the present study aims to find statistical models for estimating coffee LA in the Castillo ${ }^{\circledR}$ variety based on its dimensions.

\section{METHODS}

A total of 6,441 coffee leaves from the Castillo ${ }^{\circledR}$ variety (Coffea arabica L.) were collected from five three year-old trees (group 1) that were grown at the Central Station Naranjal of Cenicafé, located in the City of Chinchiná, Department of Caldas, Country of Colombia ( $04^{\circ} 59^{\prime} \mathrm{N}$ and $75^{\circ} 39^{\prime} \mathrm{W}$ ), at an altitude of 1,381 m, during April 2014. At this Central Station, 992 leaves from the same variety were collected in June 2014 (group 2). For each leaf, we measured the length (L), width (W), LA, and different widths along the leaf, which were used to calculate the mean width. The length from the apex to the point where the leaf joins the petiole and W from the right to the left edge at the widest point were also measured. These measurements, as well as those for LA, were performed with specialized LI-3100C Area Meter equipment for surface quantification (LI-COR, Lincoln, Nebraska). The sampling unit was the leaf in both cases, i.e., when determining the models using information from group 1 and for their validation using information from group 2.
The values of the relation $\mathrm{L} / \mathrm{W}$ gathered in three classes $(\mathrm{L} / \mathrm{W} \leq 2 ; 2<\mathrm{L} / \mathrm{W} \leq 3 ; \mathrm{L} / \mathrm{W} \geq 3)$ and were evaluated by variance analysis. The differences among classes were resolved by Duncan test at $5 \%$ of significance.

For determination of the model, LA or observed leaf area (OLA) was the dependent variable, and L, W and $\mathrm{L} \times \mathrm{W}(\mathrm{LW})$ were taken in each case as independent variables. Fits involving non-linear data were linearized (Chatterjee \& Hadi, 2006; Sit \& Poulin-Costello, 1994) to estimate the coefficients via ordinary least squares. The criteria for evaluating expressions describing LA included regression coefficients significantly different from zero based on a t-test at $1 \%$ and determination coefficients greater than $90 \%$.

Once the expressions were determined, they were applied with the values of the independent variable for group 2 , and the mean absolute relative difference (relative error) from the LA recorded for this group was estimated, determining the 75th and 99th percentiles, for the relative error. The relationship between the observed value of LA (dependent variable) and the estimated value (independent variable) was obtained using a simple linear regression model to verify that the regression coefficient was statistically equal to one using a t-test at $1 \%$. This procedure led to the conclusion that the obtained expressions do not overestimate or underestimate LA. All the statistical analyses were performed using the software SAS version 9.3 (SAS Institute, 2010).

\section{RESULTS AND DISCUSSION}

In general, the collected leaves were elliptical and between 0.76 and $140 \mathrm{~cm}^{2}$ in LA. Differences in leaf shape were classified according to $\mathrm{L} / \mathrm{W}$ in three classes according to observations made by Antunes et al. (2008). In general terms, when the value of equatorial diameter of a leaf is half or more than half of the polar diameter, the ratio is equal to or less than two. When the polar diameter exceeds the equatorial diameter more than once, the ratio will be greater than two. Table 1 shows that the average values of the L/W ratio and LA are significantly different between classes, according to the Duncan test at $5 \%$. Based on a $\mathrm{L} / \mathrm{W}$ ratio between 2 and 3, $82.7 \%$ of the evaluated leaves were classified. Therefore, leaves with a value of $L$ twice the value of $\mathrm{W}$ represented the most common shape of coffee leaves of the Castillo ${ }^{\circledR}$ variety. Leaves tending toward a circular shape (Class $\mathrm{L} / \mathrm{W} \leq 2$ ) or that were very elongated (Class L/W $\geq 3$ ) represented only 5.5 and $11.8 \%$ of the sample, respectively (Table 1). Antunes et al. (2008) found lower proportions in the sampled leaves, with $4.7 \%$ falling into the $\mathrm{L} / \mathrm{W} \leq 2$ class and $4.7 \%$ into the $\mathrm{L} / \mathrm{W} \geq 3$ class, possibly due to the mixture of Arabica and Robusta as well as Timor hybrid coffee varieties sampled.

The behavior of the OLA as a function of the length (L) or width (W) of the leaf indicated a non-linear association. 
Meanwhile, the product of $\mathrm{L}$ and $\mathrm{W}(\mathrm{LW})$ was linear in coffee of the Castillo ${ }^{\circledR}$ variety (Figure 1). Authors such as Valencia (1973) and Antunes et al. (2008) arrived at a similar conclusion when examining the dispersion patterns in coffee leaves of Arabica (Yellow Bourbom, Catuai, Mundo Novo and Tipica), Robusta (Conilon and CC 3580) and Timor hybrid varieties.

Once the behaviors shown in figure 1 were identified, a descriptive model was determined. For the figures $1 \mathrm{a}$ and $1 \mathrm{~b}$, the model corresponds to $Y=\beta_{0} X^{\beta 1}$. For the figure $1 \mathrm{c}$, it corresponds to a linear model, $Y=\beta_{0}+\beta_{1} X$. The estimated values of the coefficients are shown in table 2 . In this table, the lineal model in equation 4 did not consider the intercept because it was statistically similar to zero based on a t-test at $1 \%$.
The fourth equation involves the estimation of mean width $(Z)$ as a function of maximum width, so that the independent variable for estimating leaf area (ELA) is the product of length by the estimated mean width $\left(\mathrm{L}^{*} \mathrm{Z}\right)$.

For all expressions, the regression coefficient was significantly different from zero based on a t-test at $1 \%$, with coefficients of determination between 0.93 and 0.99 being obtained. Authors like Antunes et al. (2008), Arcila \& Chaves (1995), Awantramani \& Gopalakrishna (1965), Barros et al. (1973) and Rey \& Alvarez (1991) also have reported $\mathrm{R}^{2}$ similar in predictive of LA non-destructive for coffee leaves in function of the $\mathrm{L}$ and/or W.

With respect to the intercept, in all expressions, except for the fourth (Table 2), it was significantly different from zero

Table 1. Mean and standard error for the variables length/width (L/W) ratio and observed leaf area (OLA) in coffee of the Castillo ${ }^{\circledR}$ variety, according to the established classes

\begin{tabular}{|c|c|c|c|c|c|c|c|}
\hline \multirow{3}{*}{$\begin{array}{l}\text { Classes } \\
\text { L/W } \leq 2\end{array}$} & \multirow{3}{*}{$\begin{array}{c}\text { No. leaves } \\
355\end{array}$} & \multicolumn{3}{|c|}{ L/W Relationship } & \multicolumn{3}{|c|}{ Observed leaf area $(\mathrm{cm})$} \\
\hline & & \multicolumn{2}{|c|}{ Mean } & \multirow{2}{*}{$\begin{array}{c}\begin{array}{c}\text { Standard } \\
\text { error }\end{array} \\
0.013\end{array}$} & \multicolumn{2}{|c|}{ Mean } & \multirow{2}{*}{$\begin{array}{c}\text { Standard } \\
\text { error } \\
1.18\end{array}$} \\
\hline & & 1.7 & $\mathrm{C}$ & & 26.7 & B & \\
\hline $2<\mathrm{L} / \mathrm{W} \leq 3$ & 5348 & 2.5 & B & 0.003 & 32.6 & $A$ & 0.25 \\
\hline $\mathrm{L} / \mathrm{W} \geq 3$ & 763 & 3.4 & $A$ & 0.020 & 13.4 & C & 0.40 \\
\hline
\end{tabular}

Different letters indicate differences between means according to Duncan's test at $5 \%$.

Table 2. Estimation of the intercept and regression coefficients with their respective standard error and coefficient of determination $\left(\mathrm{R}^{2}\right)$ for each of the expressions related to the evaluated models to estimate leaf area (ELA) in individual leaves of the Castillo ${ }^{\circledR}$ coffee variety

\begin{tabular}{|c|c|c|c|c|c|c|c|c|c|}
\hline \multirow{2}{*}{ Model } & \multicolumn{3}{|c|}{ Intercept } & \multicolumn{3}{|c|}{ Regression coefficient } & \multirow{2}{*}{$\mathbf{R}^{2}$} & \multirow{2}{*}{\multicolumn{2}{|c|}{ Equation }} \\
\hline & $\beta_{0}$ & SE & $\operatorname{Pr}>|t|$ & $\beta_{1}$ & SE & $\operatorname{Pr}>|t|$ & & & \\
\hline$Y=\beta_{0} X^{\beta 1}$ & 0.19494 & 1.01685 & $<0.0001$ & 2.06621 & 0.00714 & $<0.0001$ & 0.93 & $E L A=0.19494 \times(L)^{2.06621}$ & [1] \\
\hline$Y=\beta_{0} X^{\beta 1}$ & 1.68938 & 1.00725 & $<0.0001$ & 1.87577 & 0.00496 & $<0.0001$ & 0.96 & $E L A=1.68938 \times(W)^{1.87577}$ & [2] \\
\hline$Y=\beta_{0}+X \beta_{1}$ & -0.95201 & 0.06691 & $<0.0001$ & 0.59632 & 0.00111 & $<0.0001$ & 0.98 & $E L A=-0.95201+0.59632 \times(L \times W)$ & [3] \\
\hline$Y=X \beta_{1}$ & - & - & - & 0.99927 & 0.00097 & $<0.0001$ & 0.99 & $E L A=0.99927 \times(L \times(-0.14757+0.60986 \times W))$ & [4] \\
\hline
\end{tabular}

SE: Standard error.
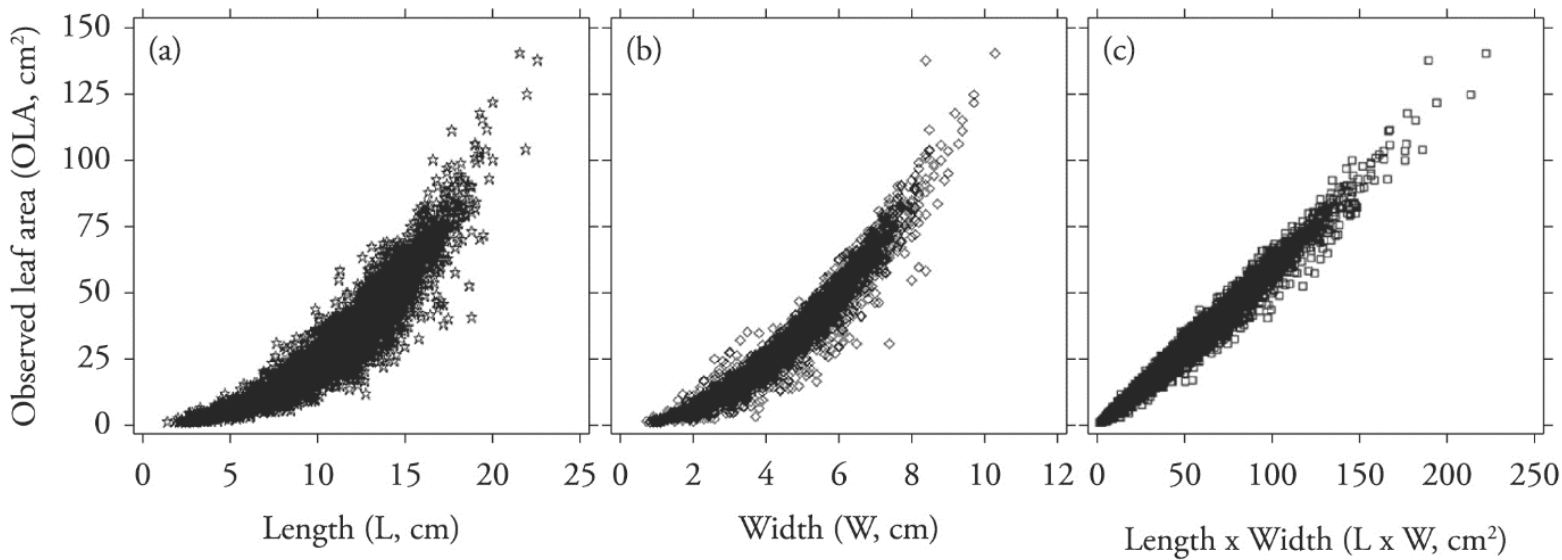

Figure 1. Behavior of the observed leaf area (OLA) as a function of: (a) length (L), (b) width (W) and (c) length*width (LW) in coffee leaves of the Castillo ${ }^{\circledR}$ variety. 
Table 3. Absolute relative error and regression coefficients between the observed (OLA) and estimated leaf area (ELA) values for Castillo ${ }^{\circledR}$ variety coffee according to the evaluated expressions

\begin{tabular}{|c|c|c|c|c|c|c|c|}
\hline \multirow{2}{*}{\multicolumn{2}{|c|}{ Equation }} & \multicolumn{3}{|c|}{ Absolute relative error (\%) } & \multirow[b]{2}{*}{$\beta_{1}$} & \multirow[b]{2}{*}{ SE } & \multirow[b]{2}{*}{$\mathbf{R}^{2}$} \\
\hline & & Mean & $\begin{array}{c}\text { 75th } \\
\text { percentile }\end{array}$ & $\begin{array}{c}\text { 99th } \\
\text { percentile }\end{array}$ & & & \\
\hline a & $E L A=0.563983 \times(L)^{2.02501}$ & 124.5 & 141.0 & 219.6 & $0.45^{* *}$ & 0.0017 & 0.98 \\
\hline [1] & $E L A=0.19494 \times(L)^{2.06621}$ & 15.8 & 21.0 & 46.7 & $1.13^{* *}$ & 0.0088 & 0.95 \\
\hline [2] & $E L A=1.68938 \times(W)^{1.87577}$ & 10.2 & 13.6 & 59.4 & $1.10^{* *}$ & 0.0073 & 0.96 \\
\hline [3] & $E L A=-0.95201+0.59632 \times(L \times W)$ & 9.2 & 10.5 & 50.2 & $1.07^{* *}$ & 0.0018 & 1.00 \\
\hline [4] & $E L A=0.99927 \times(L \times(-0.14757+0.60986 \times W))$ & 5.3 & 7.1 & 22.6 & $1.05^{* *}$ & 0.0035 & 0.99 \\
\hline
\end{tabular}

${ }^{a}$ Equation developed by Valencia (1973); ** Coefficients significantly different from one according to a t-test at $1 \%$; SE: Standard error.

according to a t-test at $1 \%$. Therefore, the fourth equation is shown only in terms of the regression coefficient.

The ELA values estimated with equation 4 showed an absolute relative error of $5.3 \%$ on average, so that there was a $75 \%$ probability that such errors were less than $7.1 \%$ and a probability of $99 \%$ that they were less than $22.6 \%$; this was the equation with the least error (Table 3). Validation of the expressions for estimating leaf area indicated overestimation with equation of Valencia (1373) and underestimation with all of the others. The regression coefficient $\left(\beta_{1}\right)$ in equation 4 , estimated as 1.05 , indicated that the observed OLA was $0.05 \mathrm{~cm}^{2}$ greater than what was estimated (ELA). For example, if leaf area is estimated to be $3.5 \mathrm{~cm}^{2}$, the observed leaf area would be $3.675 \mathrm{~cm}^{2}$ (Table 3). Field or greenhouse measurements of leaf $\mathrm{L}$ and $\mathrm{W}$ are relatively easy to perform and offer the possibility of repetition through time because of their non-destructive nature, which is a requirement of some studies on growth and development. However, if the study requires monitoring of a large number of leaves, one-dimensional models may be an acceptable option for simplifying the measurement process, although the error will be greater in relation to the real value. In this sense, it must be considered that measuring $\mathrm{L}$ is easier than measuring $\mathrm{W}$ because the latter measurement requires the consideration of an imaginary line perpendicular to the equatorial diameter of the leaf, which is not clearly defined given the irregularity of the leaf surface (Antunes et al., 2008). A practical action to measure the $\mathrm{W}$ is to bend mildly the leaf joining the apex with the petiole of the leaf, which it would permit to measure its width in more appropriate way.

\section{CONCLUSION}

In conclusion, four expressions have developed and adjusted to estimate leaf area in individual leaves of Castillo ${ }^{\circledR}$ variety coffee, based on the measurement of simple variables and non-destructive. The developed expression based on the product of $\mathrm{L}$ by W $\left(\mathrm{L}^{*} \mathrm{~W}\right)\left(\mathrm{ELA}=0.99927^{*}\left(\mathrm{~L}^{*}\left(-0.14757+0.60986^{*} \mathrm{~W}\right)\right)\right)$ showed to be the most appropriate when estimating the foliar area, with regard to the developed expressions with a single measurement of the leaf (length: $\mathrm{L}$ or width: W).
Leaf length and width explain leaf area in individual leaves, accounting for $93 \%$ and $99 \%$ of the observed variation.

\section{ACKNOWLEDGEMENTS}

This research was funded by the National Federation of Coffee Growers of Colombia and the National Coffee Research Center (Cenicafé). The authors thank Claudia Valencia, Marcela Mora and Mario Franco, technical personnel of Cenicafé, for their valuable collaboration. Thanks also go to tenured professor Dr. Enrique Martínez and to Sara Isabel Bedoya, a student in Agricultural Engineering, appointed to the Universidad Nacional de Colombia - Medellin Campus.

\section{REFERENCES}

Alvarado, A. G., Moreno, G. E., Montoya, E. C., \& Alarcón, R. (2009). Physical and in cup quality of components of the Castillo ${ }^{\circledR}$ variety and its regional derivatives. Cenicafé, 60, 210-228.

Alvarado, A. G., Posada, H. E., \& Cortina, H. A. (2005). Castillo: new coffee variety with resistance to coffee rust. (Technical Advancements, No. 337, p. 1-8). Chinchiná: Cenicafé.

Antunes, W. C., Pompelli, M. F., Carretero, D. M., \& DaMatta, F. M. (2008). Allometric models for non-destructive leaf area estimation in coffee (Coffea arabica and Coffea canephora). Annals of Applied Biology, 153, 33-40. http://dx.doi.org/10.1111/j.1744-7348.2008.00235.x.

Arcila, J., \& Chaves, B. (1995). Leaf development in the coffee tree at three sowing densities. Cenicafé, 46, 5-20.

Awantramani, D. A., \& Gopalakrishna, H. K. (1965). Measurement of leaf area (Coffea arabica L.). Indian Coffee, 29, 61-64.

Barros, R. S., Maestri, M., Vieira, M., \& Braga-Filho, L. J. (1973). Determination of leaf area in coffee (Coffea arabica L. cv. Bourbon Amarelo). Revista Ceres, 20, 44-52.

Beerling, D. J., \& Fry, J. C. (1990). A comparison of the accuracy, variability and speed of five different methods for estimating leaf area. Annals of Botany, 65, 483-488. 
Bignami, C., \& Rossini, F. (1996). Image analysis estimation of leaf area index and plant size of young hazelnut plants. Journal of Horticultural Science, 71, 113-121.

Blanco, F. F., \& Folegatti, M. V. (2005). Estimation of leaf area for greenhouse cucumber by linear measurements under salinity and grafting. Scientia Agricola, 62, 305-309. http://dx.doi.org/10.1590/ S0103-90162005000400001.

Castro-Tanzi, S., Flores, M., Wanner, N., Dietsch, T. V., Banks, J., Ureña-Retana, N., \& Chandler, M. (2014). Evaluation of a nondestructive sampling method and a statistical model for predicting fruit load on individual coffee (Coffea arabica) trees. Scientia Horticulturae, 167, 117-126. http://dx.doi.org/10.1016/j.scienta.2013.12.013.

Chatterjee, S., \& Hadi, A. S. (2006). Regression analysis by example. Hoboken: John Wiley \& Sons.

Cortina, H. A., Moncada, M. P., \& Herrera, J. C. (2012). Variedad Castillo: frequently asked questions (Technical Progress, No. 426, p. 1-12). Chinchiná: Cenicafé.

Daughtry, C. S. T. (1990). Direct measurements of canopy structure. Remote Sensing Reviews, 5, 45-60. http://dx.doi. org/10.1080/02757259009532121.

Fallovo, C., Cristofori, V., Mendoza, E., Rivera, C. M., Rea, R., \& Fanasca, S. (2008). Leaf area estimation model for small fruits from linear measurements. Horticultural Science, 43, 2267-2267.

Galindo, J. R., \& Clavijo, J. (2007). Allometric models to estimate leaflet area in peas (Pisum sativum L.). Revista Corpoica - Ciencia y Tecnología Agropecuaria, 8, 37-43.

Goudriaan, J., \& Van Laar, H. H. (1994). Modeling potential crop growth processes. Dordrecht: Kluwer Academic Publishers. 239 p.

Hein, L., \& Gatzweiler, F. (2006). The economic value of coffee (Coffea arabica) genetic resources. Ecological Economics, 60, 176-185. http://dx.doi.org/10.1016/j.ecolecon.2005.11.022.

Herbert, T. J. (2004). A simple model of canopy photosynthesis. Coral Gables: University of Miami. Retrieved in March 2014, from http://www.bio.miami.edu/tom/courses/bil160/bil160goods/ plantform/13b_plantform.html.

Ilkaee, M. N., Paknejad, F., Zavareh, M., Ardakani, M. R., \& Kashani, A. (2011). Prediction model of leaf area in soybean (Glycine max L.). American Journal of Agricultural and Biological Sciences, 6, 110-113. http://dx.doi.org/10.3844/ajabssp.2011.110.113.

International Coffee Organization - ICO (2013). All exporting countries total production. London: ICO. Retrieved in March 2014, from http://www.ico.org/historical/1990\%20onwards/PDF/1a-totalproduction.pdf.
Lizaso, J. I., Batchelor, W. D., \& Westgate, M. E. (2003). A leaf area model to simulate cultivar-specific expansion and senescence of maize leaves. Field Crops Research, 80, 1-17. http://dx.doi.org/10.1016/ S0378-4290(02)00151-X.

Lu, H. Y., Lu, C. T., Wei, M. L., \& Chan, L. F. (2004). Comparison of different methods for nondestructive leaf area estimation in taro. Agronomy Journal, 96, 448-453. http://dx.doi.org/10.2134/ agronj2004.0448.

National Federation of Coffee Growers of Colombia - FNC (2014). Report of program advancement - SICA/Technical Management. Bogotá: FNC. 123 p.

Nyakwende, E., Paull, C. J., \& Atherton, J. G. (1997). Non-destructive determination of leaf area in tomato plants using image processing. Journal of Horticultural Science, 72, 225-262.

Pandey, S. K., \& Singh, H. (2011). A simple, cost-effective method for leaf area estimation. Le Journal de Botanique, 2011, 1-6. http:// dx.doi.org/10.1155/2011/658240.

Rey, R., \& Alvarez, P. (1991). Evaluation of different regression equations for the leaf area estimation for trees in greenhouses based on linear measures. Agrotecnia de Cuba, 23, 69-74.

SAS Institute (2010). The SAS system for Windows. Release 9.3. Cary: SAS Institute.

Serdar, Ü., \& Demirsoy, H. (2006). Non-destructive leaf area estimation in chestnut. Scientia Horticulturae, 108, 227-230. http://dx.doi. org/10.1016/j.scienta.2006.01.025.

Sit, V., \& Poulin-Costello, M. (1994). Catalog of curves for curve fitting (Biometrics Information Handbook, No. 4, p. 1-11). British Columbia: Crown Publications Inc.

Sousa, E. F., Araújo, M. C., Posse, R. P., Detmann, E., Bernardo, S., Berbert, P. A., \& Santos, P. A. (2005). Estimating the total leaf area of the green dwarf coconut tree (Cocos nucifera L.). Scientia Agricola, 62, 597-600. http://dx.doi.org/10.1590/S0103-90162005000600014.

Stoppani, M. I., Wolf, R., Francescangeli, N., \& Martí, H. R. (2003). A nondestructive and rapid method for estimating leaf area of broccoli. Advances in Horticultural Science, 17, 173-175.

Valencia, A. (1973). Relationship between leaf area index and coffee tree productivity. Cenicafé, 24, 79-89.

Williams, L., 3rd., \& Martinson, T. E. (2003). Nondestructive leaf area estimation of 'Niagara' and 'DeChaunac' grapevines. Scientia Horticulturae, 98, 493-498. http://dx.doi.org/10.1016/S03044238(03)00020-7. 